\title{
Pulmonic Valve Regurgitant Jet Width
}

National Cancer Institute

\section{Source}

National Cancer Institute. Pulmonic Valve Regurgitant jet Width. NCI Thesaurus. Code C127589.

The measured width of the backflow of blood into the right ventricular outflow tract. 